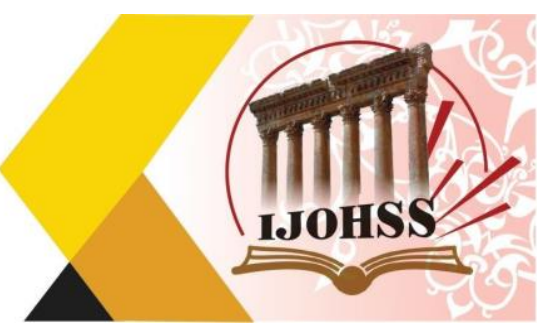

\title{
An assessment of the Impact of Leadership and Management on Performance of SMEs in Kurdistan
}

\author{
Narmen Wali Ali \\ Ministry of Higher Education and Scientific Research -Iraq \\ Email: narmen.wali@mhe-krg.org
}

\begin{abstract}
Changes in the business environment have made it essential for businesses to abandon outdated practices and processes in favour of more progressive and efficient ones. Undoubtedly, the workforce in the current job market, technology and globalisation have impacted how businesses should be operated. The purpose of this paper is to examine the impact of management and leadership on the performance of small businesses in the Kurdistan region of Iraq. The data collected in this study show that there is a positive correlation between the application of effective management and business performance. The finding of the however point that a lot of the small business in the region, unlike the larger corporations do not have clear management strategies to guide future growth. A lot of management resources and skills currently in place are geared towards meeting short-time goals and objectives.
\end{abstract}

Keywords: Impact of Leadership, SME, Kurdistan. 

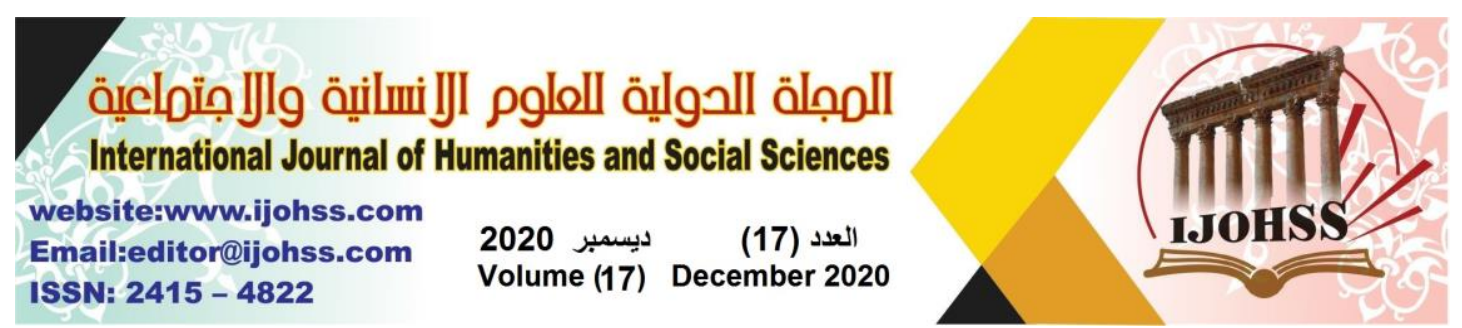

\section{Introduction.}

At the heart of any successful business are managers or leaders who make important decisions to ensure businesses remain profitable (Nienaber, 2010). These are the individuals tasked with ensuring the right strategies are adopted by a business, the correct resource is availed for the implementation of these strategies and that all activities are completed within certain timelines. They are also directly responsible for offering direction for any changes of ideas an organisation aims to adopt. Additionally, successful managers also ensure that employees are motivated and engaged to achieve overall efficiency and success in an organisation (Mládková, 2012). Managers do so much in an organisation that the leadership and management role require more of a series of key skills rather than one specific role. It broadly covers the management of people, performance and the business. Depending on the needs of a project, the employees the contextual factors that impact a business, managers interplay between providing the following; financial, logistical, motivation, supervision, time management, planning, controlling, quality assurance and rewarding functions (Armstrong \& Stephens, 2005). Management and leadership involve applying the correct skills and practices at the right time to help an organisation reach its highest potential.

The concept of management has come a long way, it was conceived during the industrial revolution. The rising number of workers in factories necessitated organising workers (Mládková, 2012). According to Mahmood et al., (2012) early theories focused more on controlling workers based on an assumption that people inherently resist work and therefore need to be prodded or sometimes even forces to be productive. Organisations at the time put a lot of effort in adopting hierarchical organisations structures that vested a lot of powers in certain individuals who were capable of punishing and rewarding workers to ensure productivity (Tuczek et al., 2018). This has however changed in recent years as a more people-friendly approached has been promoted by managerial theories to enhance performance in an organisation, as well as making the workplace safer. The economic age has also transformed the concepts of management in organisations have changed to conform to the effects of information technology and globalisation (Tuczek et al., 2018). Technology has transformed how a business operates and globalisation has changed who the employees, suppliers and customers of an organisation are. There is also an increasing acknowledgement that employees who were treated more humanely and felt appreciated by their employers tended to be more motivated, productive, innovative and loyal to their employers (Tuczek et al., 2018).

\section{Literature Review.}

Organisational performance involves the analysis of the performance of an organisation based on its set objectives and goals (Henri, 2004). According to Homburg\&Pflesser(2000) to determine the performance of an organisation, one is required to look at three main outcome areas. The first being the shareholder value, 


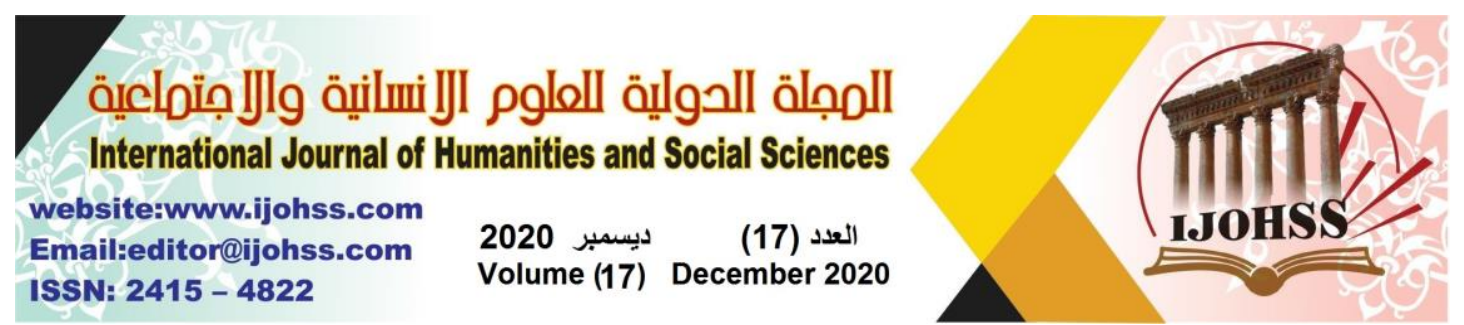

financial performance and market performance. The shareholder value measures the degree to which a business has generated profitable returns to its shareholder. Ultimately businesses are started to fundamentally bring the value of profit to shareholders. Value is simply the difference between the benefit enjoyed versus the cost incurred (Ramsay, 2005). Financial performance general measure of a firm's overall financial health over a given period. This matrix subjectively measures of how well a business can utilise its existing resources to generate revenue. The market performance of a business is measured through sales revenue, market share, profitability, competitive advantage, customer satisfaction and loyalty (Homburg \&Pflesser, 2000). Managers are individuals within an organisation who have been granted the authority and tools to make or guide decisions within an organisation to ensure efficiency and productivity.

Management and leadership are intertwined but not the same ((Mládková, 2012). Every organisation requires a little bit of management and leadership to achieve success (Armstrong \& Stephens, 2005). The first distinction is that managers usually have a clearly defined official position in an organisation. Leaders do not derive their power or ability to influence others from the structural position officially defined in an organisation. Managers have a control mindset, task-focused, they focus more on the administration processes and resource allocation and quite often are comfortable with maintaining some sort of status quo in an organisation (Zaleznik, 2004). Leaders are more persuasive, are inspirational and they welcome risks to stretch the performance of an organisation. Leaders are also very people focus which requires them to have a very sophisticated communication and interpersonal skills (Armstrong \& Stephens, 2005). Both of these sides of the coin are very important in organisations especially for smaller organisations or team setting. In budget allows it, a lot of businesses invest in both managers and leaders to balance each other out in an organisation. This also depends on the needs and nature of the business. Management can be learnt; individuals and employees can focus on acquiring the key traits that may enable them to increase their performance at an individual level as well as the overall business performance. Knowing how better to manage business processes and people will pay off in various ways (Armstrong \& Stephens, 2005).

Organisations that are thriving are those that push for higher productivity and also focus on the physical and mental well-being of their employees (Armstrong \& Stephens, 2005). The current generation of workers responds more to a humanised work environment, they expect more than just a pay check from their employers. Studies show that happy employees have fewer sick off days, are more creative, treat customers better and are generally more productive. The are several key areas of management that have shifted over the years, the first is the decision making and implementation process (Armstrong \& Stephens, 2005). Organisations are moving from a hierarchy based on authority and power and leaning more towards engaging employees at all levels of the organisation. This approach has been established to yield better decisions in organisations, increased coordination and promoted the overall support for changes in 




the organisations. The second area is how activities are coordinated throughout an organisation (Armstrong \& Stephens, 2005). A lot of the traditional bureaucracy has been replaced by agile and nimble models that allow the organisations to respond to the constantly changing pace of the current business environment. Employees are generally being granted more autonomy and independence to make the day to day decisions that drive productivity. The third area deals with how employee performance is measured (Armstrong \& Stephens, 2005). Organisations are moving away from the focus on narrow markers of achievement with more emphasis being placed on competencies that support a wider range of successful outcomes for a business. Managers have consequently reduced their reliance on rewards and punishment and are focusing more on how workers are intrinsically motivated to achieve higher productivity.

In today's modern business environment all managers are required to provide leadership to employees (Otara, 2011). Leadership allows organisations to achieve change and growth while management allows organisations to achieve order, stability and consistency. Management is also tactical and hands-on while leadership is strategic and visionary. Management is also short term and applied to achieve immediate results for the organisation (Watkins, 2012). Leadership on the other hand focuses more on the future growth on the organisation by identifying strategies and change that can better an organisation in the future. The focus in management is also internal and narrow, contrast that while leadership which is broader and external. Management also relies on the acquisition, distribution and utilization of the current resources and structures. Leadership on the other hand is responsible for designing new resources and opportunities for the future (Otara, 2011). Finally, both leadership and management deal with human resource management, however, management tends to be tactical to achieve success in the day to day performance of employees. Leadership focuses more on building that promoted employee engagement, providing inspiration, encouraging creativity, fostering collaboration and reaching out to new stakeholders to maximise the use of talent within and outside an organisation (Otara, 2011). There will always be natural tensions between when to apply management or leadership.

According to Watkins (2012) by merging management leadership, the role of a manager in an organisation has transformed to entail the following duties; the first is that the current day manager should be a producer who ensures that organisations achieve certain set tasks. The second role is that a manager is an administrator who orchestrates systems, policies and procedures that ensure an organisation runs efficiently. Mangers are also required to be innovators or promote the culture of innovation in an organisation. This ensures that organisations come up with creative solutions that increase efficiency and the overall responsiveness to projected market trends. A manager also acts as a mediator whose role is to ensure that conflicts within an organisation or between an organisation and other stakeholders are effectively handled to minimize tensions and maximize performance. Finally, modern managers are also the culture builders in an organisation, they model the pace for what the acceptable values, attitudes and acceptable behaviour that should be expected and 


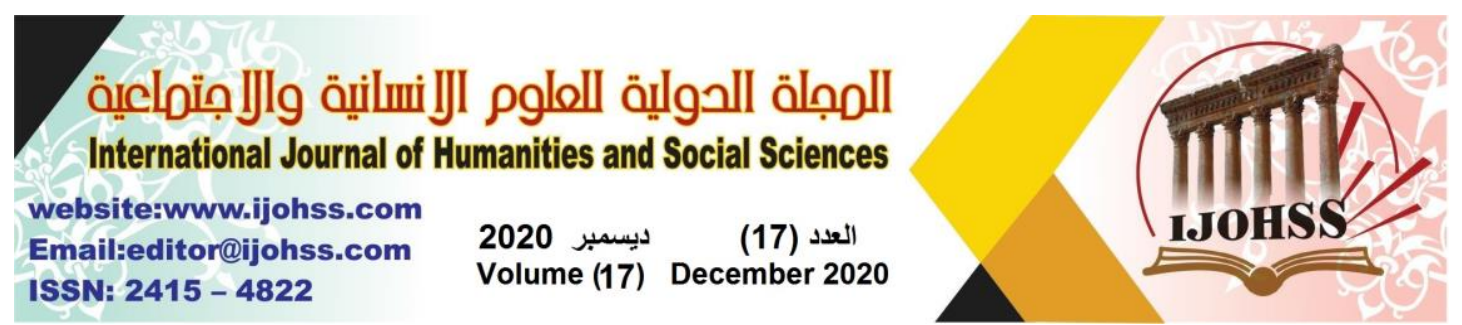

associated with an organisation. Sometime the roles may conflict, part of being a good manager is to know how to balance these roles (Zaleznik, 2004). There is an intersection between the interests of an organisation and those of employees. Effective managers know how to balance the perceptive of an organisation and those of employees (Zaleznik, 2004).

\section{Methodology}

This study will involve a desk or secondary research which relies on existing data to derive conclusions. Secondary data refers to the data that was previously collected for some other purpose other than this specific study (Ritchie \& Spencer, 2002). Due to the limitations caused by the restrictions on movement, the researcher opted to use desk research so as not put self or any subjects in immediate health danger. The method is also easier to apply, very affordable and can be achieved with the limited time frame allocated for this study (Ritchie \& Spencer, 2002). Secondary data comprises of research material published either in research journals, reports or similar documents offered a credible and convenient means for the researcher to conclude the study. The data collected from secondary sources will then be summarised and collated to enhance the general viability and effectiveness of the research. This study will use reviewed from a wealth of electronic academic material which will be accessed from online academic databases. Additionally, the study will also use online accounts and databases and rating platforms to conclude.

According to Smith et al. (2011) prescribes the following steps for conducting a secondary study in the social sciences. Like any other research project, the first step is the identification and definition of the research topic. This process involves reviewing available literature to find what has been said about the topic and the existing gaps in the area of study. This process helps to determine the best and most reliable source for the information desired and also helps the researcher to establish the best way of framing the research problem. The researcher shall define the research area as well as formulate or determine the research questions that the study is bound to answer at the end of the research.

The second step in the process involves the collection of existing data (Smith et al., 2011). This involves identifying the most appropriate data sources and which data sources can successfully be linked to fulfilling the purpose of a study. The researcher should understand the data adequately and the reasons why the specific set of data is useful to the study in question. This process is the identification, selection, analysis, linking and linking data sets to fulfil the purpose of a study. Upon successful identification of the source and area of research, the researcher should progress to the existing data collection step and subsequently breaking it down for concrete research results. The researcher should then compare existing data from variant sources and normalize such data. This requires the researcher to read everything they can access that is relevant to data to properly understand how to use the given set of data. The final step in the process is data analysis (Smith et al., 2011). The data analysis made use of 


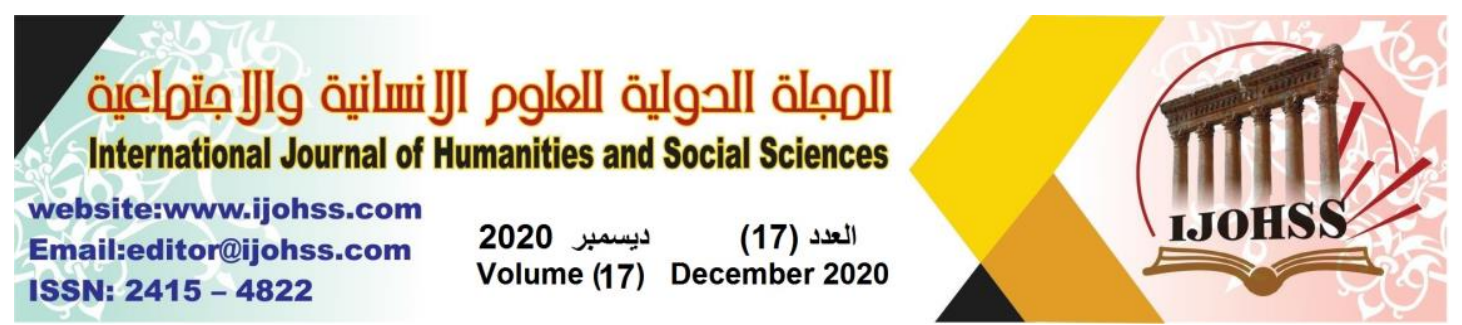

theoretical analysis. In this stage, the researcher will review the research findings and determine whether the data provides ample relevance to the research topic. The researcher is free to undertake a further review of existing data to gain actionable insight into the research topic.

Even so, there are disadvantages to secondary research. While secondary data utilizes readily available data, there is an obvious need for credibility assessment to determine information authenticity ((Ritchie \& Spencer, 2002). Additionally, not all secondary data sources could carry updated statistics and reports. Also, the validity of secondary research relies largely on the validity of primary research.

\section{Findings}

\begin{tabular}{|c|c|}
\hline Author & George O. Tasie (2017) \\
\hline Title & $\begin{array}{l}\text { Correlating Diversity of Cultures and Organization } \\
\text { Performance in Kurdistan Region of Iraq: An Empirical } \\
\text { Study }\end{array}$ \\
\hline Source & UKH Journal of Social Sciences \\
\hline Methodology & $\begin{array}{l}\text { The research made use of secondary data, oral interview and content } \\
\text { analysis. }\end{array}$ \\
\hline Findings & $\begin{array}{l}\text { There is a high level of dissatisfaction and low engagement of employees } \\
\text { in organisations in the region. Managers do not endeavour to create a } \\
\text { comfortable working environment for their employees and instil in them } \\
\text { trust and confidence. Supervisors and managers need to recognize the } \\
\text { ways in which the workplace is changing and evolving. Managerial skills } \\
\text { must adapt to accommodate the current traits of a more global work } \\
\text { environment. }\end{array}$ \\
\hline Author & Abbas Umar Ibrahim and Cross Ogohi Daniel \\
\hline Title & Impact of leadership on organisational performance \\
\hline Source & Journal of Business, Management and Social Research \\
\hline Methodology & Qualitative review of past publications and Primary data analysis \\
\hline Findings & $\begin{array}{l}\text { This implies that a unit increase in material management will lead to } \\
\text { increases in improving the company productivity. for any organization to } \\
\text { survive, appropriate impact of leadership on the employee must be } \\
\text { followed. Therefore, it is the responsibility of every leader to build an } \\
\text { organization that will function effectively because the extent to which } \\
\text { he/she succeeds will depend considerably ion subordinates willingness to } \\
\text { corporate with him/her among other things will depend on the degree of } \\
\text { congruency between the leadership style adopted by the leader and the } \\
\text { expectations and desires of the subordinates. }\end{array}$ \\
\hline Author & Rulaca Elena Hurduzeu \\
\hline Title & The Impact of leadership on Organisational Performance \\
\hline Journal & SEA- Practical Application of Science. \\
\hline Methodology & Quantitative Descriptive Statistics \\
\hline
\end{tabular}




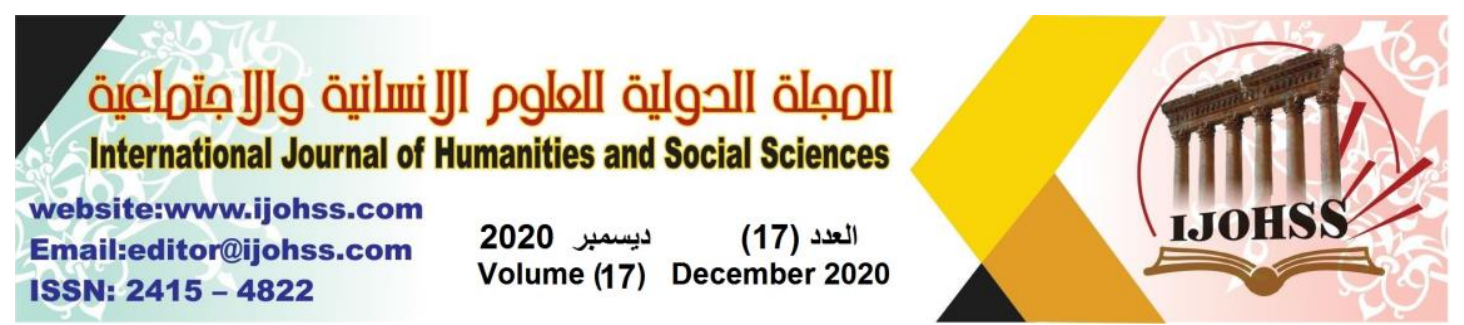

\begin{tabular}{|l|l|}
\hline Findings & $\begin{array}{l}\text { There is a positive relationship between effective leadership and } \\
\text { organisation performance as exhibited in the } 170 \text { involved in the study } \\
\text { conducted in Singapore. Effective leadership fosterers interpersonal } \\
\text { relationships within organisations that enables managers to increase } \\
\text { employee commitment, motivate employees and promote creativity. } \\
\text { There is also a long-term relationship between effective leadership when } \\
\text { applied in management has and the long-term growth of an organisation } \\
\text { in term of the financial performance and profitability through increased } \\
\text { sales and better customer service and }\end{array}$ \\
\hline
\end{tabular}

\section{Discussion.}

A lot of the small business in the Kurdistan region are small business enterprises with a very limited number of employees. Although a lot of them are family-owned, recently more foreigners are starting small business enterprises in the region. The employment landscape in the region has changed over the years as more and more children opt not to work in family businesses. This means the employment sector is expanding which has exposed some limitations in the management approaches currently in place in small businesses in the region. $t$ Private business stand to lose to bigger corporations in the capital Erbil due to loopholes in the management approach that has been adopted by the smaller organisation in the region. Findings in similar studies show that immediate profit is what drives a lot of the small business in the capital. There is very little interest or investments made in the growth and development of workers in a lot of organisations.

Findings also indicate that the younger crop of workers is not entirely comfortable with the older generations approach to managing human resource. According to the studies reviewed, although younger people are starting own businesses, a lot of the business is still owned and managed by the older generation which applies and believes in management tools of reward and punishment. Employees are not given the space to provide their input which quite often leaders to frustration. Unlike the bigger firms who recruit talent, the smaller firms recruit individuals who are the most affordable, convenient or simply just to return or earn a favour within their community. This limits the opportunity for growth and development of a vision. Industries such as the retail sector and hotel are the most adversely affected by strict application management. The findings indicate that although a lot of the business perform financially, they have not been able to grow as much because of a very limited vision for growth.

The findings also indicated that employees look up to their managers to provide them with direction, vision and motivate them. Where this is lacking employees feel restricted and are often seeking for alternative employment which means high turn over for on organisation and low productivity. 


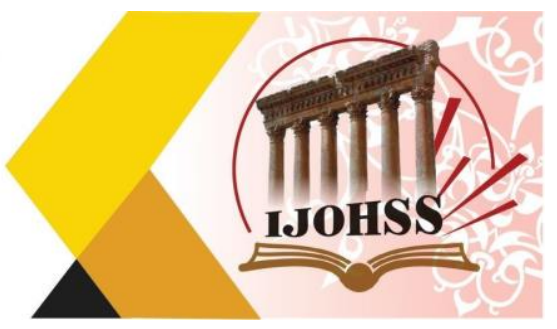

\section{Conclusion.}

Management and leadership are both very key to the overall performance of an organisation. Performance is not only limited to the financial aspects of the organisation. The employee perspective should also be factored in when analysing performance. Management alone boost the immediate performance of an organisation but fail to offer solutions and opportunities for the future growth of the organisation. Managerial skills can be learnt, thus, organisations can and should invest in teaching managers the most recent and most effective management principles and practices. This will enable managers to effectively manage and lead in an organisation. Effective leadership translates to improved performance of the organisation. Management can not entirely be ruled out, there are instances where management approaches are called for, however, leadership should also have a room with an organisation.

\section{Recommendations.}

Based on the findings and conclusions, the study recommends that;

Small businesses in the Kurdistan region should invest more in learning and keeping up to date with current trends in management to improve the performance of businesses in general. The workforce is constantly changing, young people have a lot of talent which should be applied to the smallest of businesses to escalate the personal growth of these young people as well as the performance of the businesses that employ them. Currently, very many young talented people aspire and work very hard to leave the country to work in other neighbouring countries. The stability in the region offers a lot of opportunities that cannot be harvested if the young talent is retained locally. For this to be achieved, managers even in the family-owned business need to create room for more engagement, innovation and cooperation within their businesses.

The market competition in the region has been transformed by the increase in the number of foreign-owned and operated businesses. There is potential for such businesses to completely dominate the local market in the region is proper measures are not taken to manage employee expectations. This study recommends that part of the strategies to ensure market performance is derived from management, where management fails the growth of the business is threatened, thus the small businesses need to transform some of their management approaches and attitudes to be more competitive in the market. 


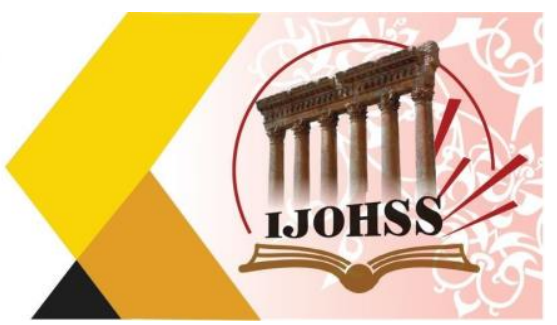

\section{References}

1. Armstrong, M., \& Stephens, T. (2005). A handbook of management and leadership: A guide to managing for results. Kogan Page Publishers.

2. Henri, J. F. (2004). Performance measurement and organizational effectiveness: Bridging the gap. Managerial finance.

3. Homburg, C., \& Pflesser, C. (2000). A multiple-layer model of market-oriented organizational culture: Measurement issues and performance outcomes. Journal of marketing research, 37(4), 449-462.

4. Hurduzeu, R. E. (2015). The impact of leadership on organizational performance. SEA-Practical Application of Science, 3(07), 289-293.

5. Ibrahim, A. U., \& Daniel, C. O. Impact of leadership on organisational performance.

6. Mahmood, Z., Basharat, M., \& Bashir, Z. (2012). Review of Classical Management Theories. International journal of social sciences \& education, 2(1).

7. Mládková, L. (2012). Leadership in management of knowledge workers. Procedia-Social and Behavioral Sciences, 41, 243-250.

8. Nienaber, H. (2010). Conceptualisation of management and leadership. Management Decision.

9. Otara, A. (2011). Perception: A guide for managers and leaders.

10. Ramsay, J. (2005). The real meaning of value in trading relationships. International Journal of Operations \& Production Management.

11. Ritchie, J., \& Spencer, L. (2002). Qualitative data analysis for applied policy research. The qualitative researcher's companion, 573(2002), 305-29.

12. Smith, J., \& Firth, J. (2011). Qualitative data analysis: the framework approach. Nurse researcher, 18(2), 52-62.

13. Tasie, G. O. (2017). Correlating Diversity of Cultures and Organisation Performance in Kurdistan Region of Iraq: An Empirical Study. UKH Journal of Social Sciences, 1(1), 1-8.

14. Tuczek, F., Castka, P., \& Wakolbinger, T. (2018). A review of management theories in the context of quality, environmental and social responsibility voluntary standards. Journal of cleaner production, 176, 399-416.

15. Watkins, M. D. (2012). How managers become leaders. The seven seismic shifts of perspective and responsibility. Harvard business review, 90(6), 64-72.

16. Zaleznik, A. (2004). Managers and leaders. Harvard Business Review, 1. 